\title{
ESTUDO DAS PRINCIPAIS CARACTERÍSTICAS EMPREENDEDORAS SOB A ÓTICA DA TEORIA DO EFFECTUATION
}

Manoel Eugênio Pereira Crispim ${ }^{1}$ Roosiley Santos Souza ${ }^{1}$

${ }^{1}$ Universidade Federal de Mato Grosso do Sul 


\section{ESTUDO DAS PRINCIPAIS CARACTERÍSTICAS EMPREENDEDORAS SOB A ÓTICA DA TEORIA DO EFFECTUATION}

Resumo: O presente estudo abordou os princípios norteadores do empreendedorismo, as características principais das pessoas com essas características, como também a teoria do Effectuation, demonstrando que as coisas podem dar certo, ainda que por caminhos diferentes do que aqueles indicados pelas teorias empresariais ou causual. Adotou-se a pesquisa do tipo qualitativa-descritiva, pelo fato de o pesquisador ter mantido contato direto e prolongado com o ambiente e toda situação que envolve o contexto do estudo. Quanto à classificação, tratou-se de um estudo de caso, por se tratar de estudo profundo dos fatos objetos de investigação, permitindo um amplo e pormenorizado conhecimento da realidade e dos fenômenos pesquisados. A análise que evidenciou os resultados foi do tipo de análise por categoria. Os resultados demonstram que a empresária do setor de turismo no município de Corumbá (MS) apresenta as características empreendedoras sob a ótica da Teoria Effectuation.

Palavras-chave: Empreendedorismo. Teoria Efecctuation. Características Empreendedoras. Turismo.

\section{Introdução}

As mudanças advindas do processo de globalização e do desenvolvimento tecnológico tornaram o mercado mais dinâmico e competitivo. Neste contexto, as tendências do mercado globalizado e competitivo determinam que as empresas sejam proativas e antecipem-se às mudanças e a demanda. Para enfrentar as mudanças, diversos autores exaltam a necessidade da figura do empreendedor. Para Filion (1999, p. 19) empreendedor é "[...] uma pessoa que imagina, desenvolve e realizam visões". Na mesma vertente, Hisrich (2004) diz que:

O empreendedorismo é o processo de criar algo diferente e com valor, dedicando o tempo e o esforço necessário, assumindo os riscos financeiros e sociais correspondentes e recebendo as consequentes recompensas da satisfação econômica e pessoal. (HISRICH, p. 29, 2004).

Mas o que seriam os processos? De acordo com Hammer e Champy (1994 apud GONÇALVES, 2000, p. 7) é "um grupo de atividades realizadas numa sequência lógica com o objetivo de produzir um bem ou serviço que tem valor para um grupo específico de clientes". Sendo assim, ao se observar tudo dentro de uma organização é processo, desde a definição de sua visão e missão, até gestão de caixa, pesquisa de mercado, planejamento da produção, dentre outros também chamados de modelo casual.

Uma série de estudos na literatura busca compreender fatores associados ao ato de empreender e o processo de criação e desenvolvimento de uma empresa. Um campo de estudo nessa vertente, temos a proposta da pesquisadora e professora Saras Sarasvathy que apresenta uma análise a respeito da criação e desenvolvimento de novos mercados, ao recomendar um modelo de decisão que denominou de Effectuation como alternativa ao modelo de decisão clássico que se baseia no princípio da causalidade. 
O que motivou o desenvolvimento deste tema, para tanto, foi a proposta de identificar e analisar características de empresários já estabelecidos na cidade de Corumbá (MS), entender como os empreendedores decidiram iniciar suas empresas e estruturar novos negócios sem uma definição clara e objetivo pré-estabelecido, de que maneira se valeram do effectuation e suas ferramentas. Complementando, a proposta deste estudo está alinhada ao Projeto de Extensão: Análises das Características Empreendedoras sob a ótica da Teoria do Effectuation, do qual faço parte.

Numa busca em periódicos nacionais na área de empreendedorismo, esta pesquisa encontrou poucos dados, e estudos específicos desenvolvidos na cidade, que abordavam a temática da Teoria Effectuation. Nesta perspectiva, o presente estudo de caso visa identificar as características empreendedoras de uma empresária do setor de turismo de pesca na cidade de Corumbá (MS).

Tendo em vista que muitas pessoas têm as mesmas oportunidades, mas apenas algumas conseguem se destacar, pretende-se analisar o perfil da empresária, sem uma formação profissional específica, ou seja, sem conhecimento teórico científico.

Diante do exposto, as perguntas norteadoras deste estudo foram: Quais as características natas e desenvolvidas por essa empresária que norteiam o seu comportamento e atitudes, que nos levam a entender que ela é empreendedora? As suas características são as preconizadas na teoria Effectuation? Como ocorreu o processo de decisão desta empreendedora ao abrir um novo negócio?

O presente estudo foi realizado na cidade de Corumbá, Mato Grosso do Sul. De acordo com dados do IBGE (2013), Corumbá está situada a cerca de 420 quilômetros da capital Campo Grande e é considerada historicamente o primeiro polo de desenvolvimento da região. Por abrigar 50\% do território pantaneiro, ficou bem conhecida como Capital do Pantanal, além de ser a principal e mais importante zona urbana da região alagada. Ainda segundo o IBGE (2013), a cidade tem atualmente uma população estimada em 108.010 habitantes, fato que a torna a terceira maior cidade do estado em termos populacionais. As atividades econômicas, em Corumbá (MS) são a pecuária, a pesca, o turismo, a extração de minérios, a agricultura, o comércio de mercadorias e a prestação de serviços diversos. O turismo de pesca é a atividade de destaque quando o destino turístico é Corumbá (MS).

\section{Referencial Teórico}

\subsection{Empreendedorismo}

Um primeiro exemplo de definição de empreendedorismo pode ser creditado a Marco Polo que tentou estabelecer uma rota comercial para o oriente. Como empreendedor, Marco Polo assinou um contrato com um homem que possuía dinheiro (hoje mais conhecido capitalista) para vender as mercadorias deste. Enquanto o capitalista era alguém que assumia risco de forma passiva, o aventureiro empreendedor assumia papel ativo, correndo todos os riscos físicos e emocionais. (DORNELAS, 2000, p. 27).

A palavra empreendedor tem origem francesa "entrepreneur" e hoje quer dizer aquele que assume riscos e começa algo novo. (DORNELAS, 2005,P.29).

Reportando ao Brasil, Brito (2014) diz que o empreendedorismo no Brasil foi popularizado pelo economista Joseph Schumpeter, em 1945, com sua teoria da Destruição 
Criativa. Para Schumpeter, o empreendedor é alguém versátil, que possui as habilidades técnicas para saber produzir, e capitalista, que consegue reunir recursos financeiros, organizar as operações internas e realizar as vendas da sua empresa.

Na visão de Hisrich (2004):

O empreendedorismo é o processo de criar algo diferente e com valor, dedicando o tempo e o esforço necessário, assumindo os riscos financeiros e sociais correspondentes e recebendo as consequentes recompensas da satisfação econômica e pessoal. (HISRICH, 2004, p. 29).

Uma grande característica entre os empreendedores é a capacidade de enxergar oportunidades que são subjetivas, existe apenas na mente de quem decide (KLEIN, 2008).

Características como a persistência, são movidas por ideais, sonhos. Acreditam no impossível, andam na contramão, são curiosos, enxergam o mundo de maneira diferente, estão sempre usando a criatividade, ousando, dão mais créditos à imaginação que ao conhecimento e tem consciência que o sucesso é apenas consequência de um trabalho bem feito. É a personalidade criativa; sempre lidando melhor com o desconhecido, perscrutando o futuro, transformando possibilidades em probabilidades, caos em harmonia (GERBER, 1996).

Segundo a Global Entrepreneuship Monitor, apenas 14\% dos empreendedores no Brasil tem formação universitária e 30\% sequer concluíram o ensino fundamental (GEM, 2000). Dessa maneira, os sujeitos acabam desenvolvendo as características empreendedoras com base em experiências vividas, acumulando um conhecimento empírico.

\subsection{Características Empreendedoras}

No Brasil é certo dizer que é muito difícil abrir e manter um negócio, devido ao excesso de burocracia e às altas taxas tributarias, não bastando somente uma boa ideia. É preciso ter muito jogo de cintura. No relatório executivo de 2000 do Global Entrepreneurship Monitor (GEM, 2000), o Brasil aparece como o país que possui a melhor relação entre o número de habitantes adultos que começam um novo negócio e o total dessa população: 1 em cada 10, [...] na Irlanda e no Japão, 1 em cada 100 (DORNELAS, 2000, p. 26).

Apesar de toda falta de apoio do poder público e financeiro, o brasileiro tende a arriscar, seja por oportunidade ou por necessidade, já que muitas vezes não se tem uma opção de escolha.

Desde o ano 2000 ocorreram mudanças significativas nesse quadro, como demonstrado na pesquisa GEM de 2017. De acordo com a pesquisa, no Brasil, a taxa total de empreendedorismo (TTE) foi de $36,4 \%$, o que significa que de cada 100 brasileiros e brasileiras adultos (18 - 64 anos), 36 deles estavam conduzindo alguma atividade empreendedora, quer seja na criação ou aperfeiçoamento de um novo negócio, ou na manutenção de um negócio já estabelecido. A referida informação pode ser constatada na Tabela 1, que em números absolutos representa dizer que é de quase 50 milhões o contingente de brasileiros que já empreendem e/ou realizaram, em 2017, alguma ação visando a criação de um empreendimento num futuro próximo. 
Tabela 1 - Taxas (em \%) e estimativas (em unidades) de empreendedorismo, segundo o estágio dos empreendimentos Brasil 2017.

\begin{tabular}{lcc}
\hline Estágio & Taxas & Estimativas \\
\hline TOTAL DE EMPREENDEDORES & 36,4 & 49.332 .360 \\
Iniciais & 20,3 & 27.482 .078 \\
Novos & 16,3 & 22.093 .966 \\
Nascentes & 4,4 & 6.010 .858 \\
Estabelecidos & 16,5 & 22.337 .649 \\
\hline
\end{tabular}

Fonte: GEN (2017). Percentual da população de 18 a 64 anos. Estimativas calculadas a partir de dados da população brasileira de 18 a 6 anos para o Brasil em 2017. Fonte: IBGE/Diretoria de pesquisas projeção da população do Brasil e unidades da federação por sexo e idade para o período 2000-2030 (ano 2017).

Com base no Gráfico 1 abaixo, fica clara a onda crescente do empreendedorismo mostrando que o brasileiro tende a se arriscar e aquele que tem um feeling mais apurado consegue se sobressair.

Gráfico 1 - Taxas1 (em\%) de empreendedorismo segundo estágio do empreendimento TEA, TEE, TTE - Brasil 2002-2017.

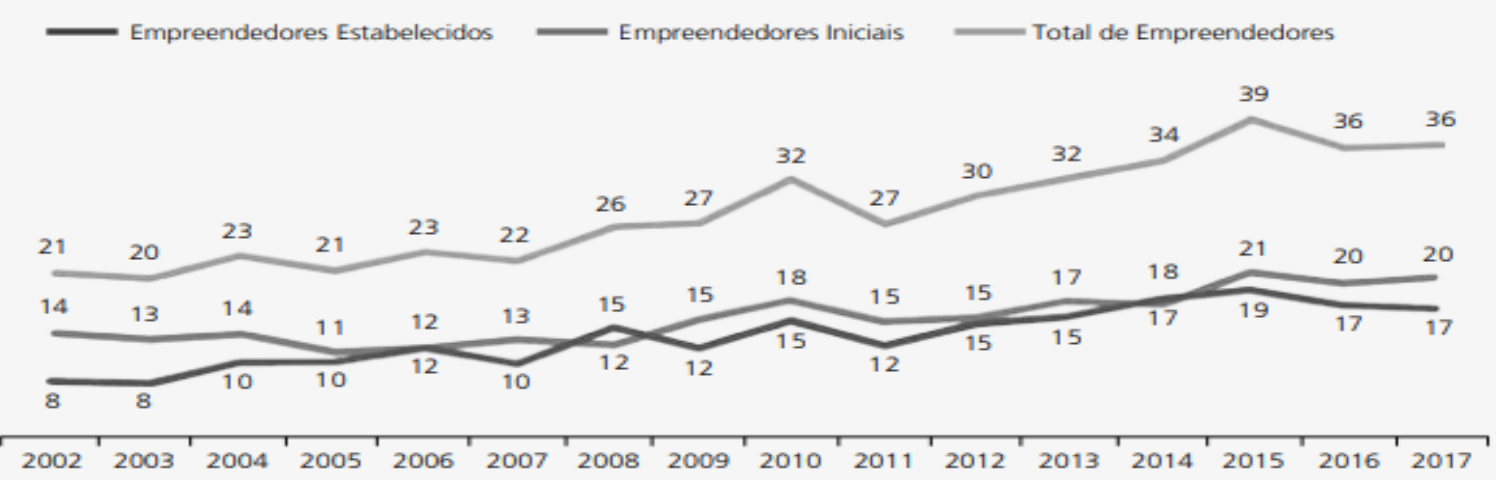

Fonte: GEM Brasil 2017 (Percentual da população de 18 a 64 anos).

Segundo o empresário Abílio Diniz (2000), as pessoas não nascem empreendedoras, mas sim com características que ajudarão a se tornar um. O empreendedor de sucesso possui características extras além dos atributos do administrador, e alguns atributos pessoais que, somados a características sociológicas e ambientais, permitem o nascimento de uma nova empresa.

De uma boa ideia, surge uma inovação, e desta ideia uma empresa (DORNELAS, 2000). Nessa linha de raciocínio, as principais características empreendedoras são: São visionários, Sabem tomar decisões, São indivíduos que fazem a diferença, Sabem explorar ao máximo as oportunidades, São dedicados, São otimistas e apaixonados pelo que fazem, São independentes e constroem o próprio destino, Ficam ricos, São líderes e formadores de equipes, São bem racionados (networking), São organizados, Planejam, Planejam, Planejam, Possuem conhecimento, Assumem riscos calculados, Criam valor para sociedade.

Ainda de acordo com Pelagio e Rocha (1999, apud FILION, 2016) o que diferencia o empreendedor e o caracteriza é uma estrutura de pensamentos sistêmicos e visionário, de 
maneira que não se prende a ordem natural, ou a lógica buscando meios e alternativas como o effectuation, usando as instrumentos que tem em busca de alcançar os objetivos.

\subsection{Teoria do effectuation}

A teoria do effectuation desenvolvida pela professora Saras Sarasvathy quebra o paradigma de que o empreendedor para ter sucesso em seu negócio tenha que partir da lógica casual com base em um plano de negócio, pesquisa de mercado e uma busca desesperado por um alto capital.

Para Sarasvathy (2001) o effectuation é o oposto da lógica causual salientando que, enquanto o raciocínio causal parte de um objetivo pré-determinado e um conjunto de meios disponíveis para procurar a melhor forma de atingir esse objetivo (GONZÁLEZ, AÑEZ, MACHADO, 2011) modelo padrão do mundo dos negócios. Porém, a lógica causual é de suma importância para as empresas já estruturadas.

A teoria do effectuation não começa com um objetivo específico, e sim com um conjunto de meios a partir dos quais irão surgindo diferentes objetivos (GONZÁLEZ, AÑEZ, MACHADO, 2011) salientando que uma teoria não exclui a outra, sendo usadas em diferentes tempos, explicando a existência de empresas que começaram como startups ou de maneira informal, e hoje são empresas de renome e de grande importância para o mercado nacional e global, utilizando de maneira consciente ou inconsciente os cinco princípios: Pássaro na mão; Perdas toleráveis; Colcha de retalhos; Fazer do limão uma limonada e Piloto de Avião, apresentados nos quadros 1, 2, 3, 4 e 5 a seguir:

Quadro 1 - Pássaro na mão

\begin{tabular}{|l|l|}
\hline \multirow{5}{*}{ Pássaro na mão } & $\begin{array}{l}\text { (começar com o seu meio e trabalhar com o que se tem) } \\
\text { É possível começar um negócio com seus próprios meios, com o ‘pássaro que você } \\
\text { tem nas mãos'. O ponto de partida são três perguntas-chave: Quem eu sou? O que } \\
\text { eu sei? Quem eu conheço? Fazendo uma analogia com comida, Saras diz que, na } \\
\text { lógica causal, as pessoas seguiriam uma receita de comida que foi pré-determinada } \\
\text { e preparada com antecedência. Já na teoria do Effectuation, a comida é preparada a } \\
\text { partir do que há dentro da geladeira - decide-se na hora o que preparar com a } \\
\text { experiência que já se tem. }\end{array}$ \\
\hline
\end{tabular}

Fonte: Aliança empreendedor.

Busca-se identificar oportunidades a partir dos recursos disponíveis, trabalhando com o que tem, com o que sabem e de experiências já vivenciadas.

Quadro 2 - Perdas toleráveis

\begin{tabular}{|l|l|}
\hline \multirow{3}{*}{ Perdas toleráveis } & $\begin{array}{l}\text { Em vez de focar no possível retorno, pensar nas possíveis perdas e em como } \\
\text { minimizar isso. "Comece com um negócio simples, não importa sua formação. O } \\
\text { princípio é dar o primeiro passo e como fazer quando tomar o primeiro tombo", diz } \\
\text { Saras. O empreendedor eficaz não investe tudo o que tem, mas sim a quantia que } \\
\text { pode perder. A ideia é não investir mais do que se pode arcar com o prejuízo. Não } \\
\text { investir mais do que pode perder. }\end{array}$ \\
\hline
\end{tabular}

Fonte: Aliança empreendedora 
Convém pensar de maneira responsável quanto aos recursos financeiros, pois além de tempo e reputação que estarão em jogo, o retorno deverá estar diretamente ligado ao grau de risco do investimento.

Quadro 3 - Colcha de retalhos

\begin{tabular}{|l|l|}
\hline \multirow{5}{*}{ Colcha de retalhos } & $\begin{array}{l}\text { Enquanto o pensamento causal vê um problema a ser resolvido como peças de } \\
\text { quebra-cabeças - predeterminadas e com previsibilidade -, no Effectuation o } \\
\text { problema está mais para uma colcha de retalhos, que vai ganhando forma na } \\
\text { medida em que vai sendo construída. O futuro é construído a partir do que as } \\
\text { pessoas fazem. Novos mercados e produtos surgem a partir de restrições e } \\
\text { oportunidades geradas por pessoas que trazem recursos. Por isso, é importante } \\
\text { um comprometimento com alianças estratégicas, parceiros com habilidades } \\
\text { complementares. }\end{array}$ \\
\hline
\end{tabular}

Fonte: Aliança empreendedora

Sua ideia original pode ser a base do seu negócio, mas ela deve ser aprimorada, de acordo com as influências externas e se moldando conforme a exigência do mercado.

Quadro 4 - Fazer do limão uma limonada

\begin{tabular}{|l|l|}
\hline $\begin{array}{l}\text { Fazer do limão uma } \\
\text { limonada }\end{array}$ & $\begin{array}{l}\text { As coisas podem dar erradas, claro. E as surpresas não são necessariamente } \\
\text { coisas ruins. Podem e devem ser exploradas para descobrir novas oportunidades } \\
\text { e mercados. "Você vai encontrar rejeição, fracasso, e tem que transformar essas } \\
\text { coisas o tempo todo. Temos que nos adaptar", diz Saras. }\end{array}$ \\
\hline
\end{tabular}

Fonte: Aliança empreendedora.

Saber lidar com imprevistos e considerá-los parte do negócio. As coisas podem não sair como planejados. O dia a dia no mundo dos negócios é uma caixinha de surpresa, e essas situações estão além das nossas vontades. É necessário autoconhecimento e estar disposto a usar esses contratempos ao seu favor e não os evitar.

Quadro 5 - O piloto do avião

\begin{tabular}{|l|l|}
\hline O piloto do avião & $\begin{array}{l}\text { Uma quantidade pequena de negócios hoje bem-sucedidos já começou grande. } \\
\text { A maioria deles surgiu pequena, pois como exemplifica a própria prof }{ }^{\text {a }} \text { Saras, } \\
\text { existe uma distância grande entre servir uma refeição e construir uma rede de } \\
\text { restaurantes. O futuro não pode ser previsto, mas empreendedores podem } \\
\text { controlar alguns fatores que são determinantes. }\end{array}$ \\
\hline
\end{tabular}

Fonte: Aliança empreendedora.

Quando não se pode prever o futuro, você deve controlá-lo, o interessante saber quando é hora de corrigir erros que serão identificados de acordo com a experiência adquirida.

\subsubsection{Causation $x$ Effectuation}

A noção da institucionalização de algumas práticas gerenciais, tais como a necessidade de planos estratégicos e a quantificação de cenários futuros, ajuda a entender alguns dos fenômenos por trás da visão clássica de causalidade e escolha racional dos agentes, em especial dos empreendedores (PELAGIO e ROCHA, 2016, p. 216). 
A ideia de effectuation se opõe à lógica de causalidade clássica (causation). Ambos os modelos de decisão, seguidos de exemplos e evidências com o objetivo de tornar distinção mais clara (TASIC, 2007, pp. 28-29).

Quadro 6-Modelos de decisão

\begin{tabular}{|c|c|c|}
\hline QUESTÕES & POSIÇÃO CAUSUAL OU PREDITIVA & POSIÇÃO EFFECTUAL \\
\hline Visão de futuro & $\begin{array}{l}\text { Predição. A abordagem causual vê o futuro } \\
\text { como uma continuação do passado que pode, } \\
\text { normalmente ser aceitavelmente predito. }\end{array}$ & $\begin{array}{l}\text { Criação. A abordagem effectual vê o } \\
\text { futuro como dependentes de ações de } \\
\text { agentes obstinados. Predição e um } \\
\text { resultado sem importância. }\end{array}$ \\
\hline $\begin{array}{l}\text { Base para com- } \\
\text { prometimento }\end{array}$ & $\begin{array}{l}\text { Deveria. Faça o que você deveria fazer, baseado } \\
\text { em análises e maximização. }\end{array}$ & $\begin{array}{l}\text { Pode. Faça o que você e capaz de fazer } \\
\text { em imaginação e satisfação. }\end{array}$ \\
\hline $\begin{array}{l}\text { Base para entra } \\
\text { em ação }\end{array}$ & $\begin{array}{l}\text { Cenários desejados. A visão de um cenário } \\
\text { desejado determina as metas determinam as } \\
\text { submetas comprometimentos e ações. }\end{array}$ & $\begin{array}{l}\text { Cenários possíveis. Meios e } \\
\text { comprometimentos dos stakeholders } \\
\text { determinam possíveis submetas, sendo } \\
\text { que as metas surgem da agregação de } \\
\text { submetas. }\end{array}$ \\
\hline $\begin{array}{l}\text { Base para } \\
\text { adquirir } \\
\text { stakeholders }\end{array}$ & $\begin{array}{l}\text { Visão instrumental dos stakeholders. Os } \\
\text { objetivos do projeto determinam quem deve } \\
\text { ingressar. }\end{array}$ & $\begin{array}{l}\text { Visão instrumental dos objetivos. } \\
\text { Quem ingressa num projeto determina } \\
\text { seus objetivos. }\end{array}$ \\
\hline Planejamento & $\begin{array}{l}\text { Comprometimento. Seleção de caminhos e } \\
\text { limitada por aqueles que sustentam um } \\
\text { compromisso com um objetivo existente. }\end{array}$ & $\begin{array}{l}\text { Contingência. São escolhidos os } \\
\text { caminhos que permitem mais opções } \\
\text { possíveis habilitando a troca de } \\
\text { estratégias quando necessário. }\end{array}$ \\
\hline $\begin{array}{l}\text { Predisposição a } \\
\text { risco }\end{array}$ & $\begin{array}{l}\text { Retorno esperado. Calcula o potencial de ganho } \\
\text { e busca a melhor oportunidade, ajustando-se o } \\
\text { risco. }\end{array}$ & $\begin{array}{l}\text { Perda disponível. Calcula o potencial } \\
\text { de perda e não arrisca mais do que pode } \\
\text { dispor a perder. }\end{array}$ \\
\hline $\begin{array}{l}\text { Atitude com em- } \\
\text { presas externas }\end{array}$ & $\begin{array}{l}\text { Competição. Restringe relações de tarefas com } \\
\text { clientes e fornecedores ao que se necessário. }\end{array}$ & $\begin{array}{l}\text { Parceria. Constrói seu mercado } \\
\text { juntamente com clientes, fornecedores } \\
\text { e, até mesmo concorrentes em } \\
\text { potencial. }\end{array}$ \\
\hline
\end{tabular}

Fonte: Pelagio e Rocha (2016)

De acordo com Tasic (2007, p. 63) que adota um método dialético, ainda que breve, na tentativa de definir de forma mutuamente exclusiva o que é effectuation, à medida que se demonstra o que não é effectuation, vale-se essencialmente da discussão proposta por Sarasvathy et al (2005), conforme apresentamos a seguir na Tabela 2.

Tabela 2 - O que é Effectuation e o que Effectuation não é
EFFECTUATION NÃO É...
EFFECTUATION...

\begin{tabular}{|c|c|}
\hline $\begin{array}{l}\text { 1. Um conjunto de desvios heurísticos a partir da } \\
\text { ideia de escolhas racionais }\end{array}$ & $\begin{array}{l}\text { É um paradigma alternativo que não se sobrepõe à } \\
\text { ideia de escolhas racionais }\end{array}$ \\
\hline $\begin{array}{l}\text { 2. Uma substituição genérica para a ideia de } \\
\text { racionalidade preditiva }\end{array}$ & Existe em paralelo à ideia de racionalidade preditiva \\
\hline 3. Irracional ou não-racional & $\begin{array}{l}\text { Ajuda, em conjunto com outras noções, a pluralizar a } \\
\text { noção de racionalidade, e não negá-la }\end{array}$ \\
\hline
\end{tabular}




\section{4.um processo aleatório}

\section{Uma teoria em que "vale qualquer coisa"}

6. Uma visão baseada em recursos do processo decisório individual

7. Apenas para empresas de pequeno, médio porte ou start-ups

\section{Restrita ao domínio do empreendedorismo}

9. Uma teoria independente
É sistemático e desenvolvido, com princípios eminentemente assimiláveis e ensináveis, bem como prescrições práticas própria

É uma teoria de criatividade restringida

Não assume a pré-existência de recursos valiosos, questiona, sim, o que torna as coisas valiosas e como alguém pode adquiri-las e/ou criar valor nos recursos Pode ser aplicada tanto para grandes empresas quanto para economias em geral

Assim como a filosofia da escolha racional, ela pode unificar todas as ciências da ação humana

Integra o trabalho e constrói sobre diversas teorias bem sedimentadas no campo da economia e gestão

Fonte: Tasic (2007, p. 63).

A partir da explanação de Tasic (apud SARASVATHY et al, 2005, p. 63) fica claro que o effectuation é uma teoria que veio fundamentar ações de pessoas que com seus conhecimento, habilidades e atitudes (CHA) são capazes de empreender, criar novos negócios, ir além do que a normalidade diz que é possível, não se limitando as imposições impostas pelo mercado.

Para Sarasvathy (2011, p. 1), effectuation é a resposta para as perguntas de como os empreendedores fazem para tomar decisão e agir em meio às incertezas e uma alternativa para a criação de novas empresas.

\section{Metodologia}

Quanto à classificação quanto à natureza da pesquisa, consoante Bogdan \& Biklen (1994), a pesquisa que estruturou este estudo foi configurada como qualitativa-descritiva, por apresentar as seguintes características:
a) "Na investigação qualitativa a fonte direta de dados é o ambiente natural, constituindo o investigador o instrumento principal".
b) "A investigação qualitativa é descritiva".
c) "Os investigadores qualitativos interessam-se mais pelo processo que simplesmente pelos resultados ou produtos".
d) "O significado é de importância vital na abordagem qualitativa".
e) "Os investigadores qualitativos tendem a analisar os dados de forma indutiva" (BOGDAN \& BIKLEN, 1994, p. 47-51).

A pesquisa do tipo qualitativa-descritiva, segundo os autores Bogdan \& Biklen (1994), prevê que o pesquisador mantém contato direto e prolongado com o ambiente e toda situação que envolve o contexto do estudo. Por tratar-se de uma investigação pautada em comportamento humano e considerando que este sofre influências significativas do contexto em que se encontra, é preciso estar atento para os procedimentos e interações cotidianas e saber que se trata de uma sistemática que através dessa pesquisa conseguimos retratar.

Quanto à classificação e escolha do objeto de estudo, a pesquisa foi classificada como um estudo de caso único que segundo Yin (2001, p. 29) "[...] o estudo de caso é caracterizado 
pelo estudo profundo e exaustivo dos fatos objetos de investigação, permitindo um amplo e pormenorizado conhecimento da realidade e dos fenômenos pesquisados".

Ainda de acordo com o autor "Um estudo de caso é uma investigação empírica que investiga um fenômeno contemporâneo dentro do seu contexto da vida real, especialmente quando os limites entre o fenômeno e o contexto não estão claramente definidos" (YIN, 2001, p. 33).

Para Triviños (1987), o estudo de caso é uma categoria de pesquisa cujo objeto é uma unidade que se analisa profundamente.

Ainda nessa linha de raciocínio, Yin (2001, p. 28) considera o estudo de caso como uma estratégia de pesquisa que possui uma vantagem específica quando: "faz-se uma questão tipo 'como' ou 'por que' sobre um conjunto contemporâneo de acontecimentos sobre o qual o pesquisador tem pouco ou nenhum controle".

A investigação de estudo de caso enfrenta uma situação tecnicamente única em que haverá muito mais variáveis de interesse do que pontos de dados, e, como resultado, baseia-se em várias fontes de evidências, com os dados precisando convergir em um formato de triângulo, e, como outro resultado, beneficia-se do desenvolvimento prévio de proposições teóricas para conduzir a coleta e a análise de dados. (YIN, 2001, pp. 33-34).

No que diz respeito aos procedimentos operacionais concernentes, tanto à fundamentação teórica, quanto ao trabalho de campo, optamos por diferentes maneiras procedimentais, envolvendo visita in loco, coleta e obtenção de dados e informações por meio de pesquisa bibliográfica tendo como fonte livros, artigos, teses, dissertações e sites especializados sobre o tema.

O instrumento de coletas de dados escolhido foi do tipo entrevista semiestruturada. De acordo com Cervo \& Bervian (2002), é uma das principais técnicas de coletas de dados e pode ser definida como conversa realizada face a face pelo pesquisador junto ao entrevistado, seguindo um método para se obter informações sobre determinado assunto

As entrevistas semiestruturadas podem ser definidas como uma lista das informações que se deseja de cada entrevistado, mas a forma de perguntar (a estrutura da pergunta) e a ordem em que as questões são feitas irão variar de acordo com as características de cada entrevistado. Geralmente, as entrevistas semiestruturadas baseiam-se em um roteiro constituído de [...] uma série de perguntas abertas, feitas verbalmente em uma ordem prevista, apoiadas no quadro teórico, nos objetivos e nas hipóteses da pesquisa. Durante a realização da entrevista é importante seguir algumas recomendações, tais como fazer boas perguntas e interpretar as respostas; ser um bom ouvinte, não deixando se enganar por ideologias e preconceitos, no sentido de buscar a 'objetivação' (LAVILLE e DIONNE, 1999, p. 188).

A entrevista foi realizada com o intuito de levantarmos dados e informações sobre o perfil empreendedor do proprietário de um negócio de acordo com o preconizado na teoria effectuation, descrever como ocorreu o processo de decisão deste empreendedor ao abrir um negócio e verificar quais ferramentas utilizou no processo de abertura do negócio e relacionar se as mesmas podem ser caracterizadas de acordo, com o indicado na teoria do effectuation; 
A entrevista foi semiestruturada e as partes que elucidam o objetivo das análises, foram apresentadas por categorias, que segundo Minayo (1994, p. 70):

A palavra categoria, em geral, se refere a um conceito que abrange elementos ou aspectos com características comuns ou que se relacionam entre si. [...] As categorias são empregadas para se estabelecer classificações. Nesse sentido, trabalhar com elas significa agrupar elementos, ideias ou expressões em torno de um conceito capaz de abranger tudo isso. [...] As categorias podem ser estabelecidas [...] a partir da coleta de dados, são mais especificas e mais concretas.

Para esclarecermos a análise por categorias, recorremos a Franco (2003, p.59), que menciona: [...] um conjunto de categorias satisfatórias deve possuir as seguintes qualidades: a exclusão mútua, a pertinência, a objetividade e a fidedignidade e a produtividade.

Ao tratar sobre as qualidades usadas nas análises por categoria, a autora nos permitiu entender que há um único princípio de classificação que devia ser escolhido para orientar a organização das entrevistas; estas deviam refletir as intenções da investigação mesmo quando submetidas a várias análises e ser capaz de orientar-nos para uma prática crítica, construtiva e transformadora.

Ao propormos uma discussão sobre a teoria effectuation, utilizamos os cinco princípios: Pássaro na mão; Perdas toleráveis; Colcha de retalhos; Fazer do limão uma limonada e Piloto de Avião.

As análises e discussões dos resultados foram realizadas com o intuito de atendermos os objetivos que nortearam este estudo, a fim de compararmos e confrontarmos dados e provas que tiveram como objetivo confirmar os pressupostos da pesquisa.

\section{Apresentação dos Resultados e análise}

Apresenta-se a análise e interpretação dos dados coletados, tendo em vista os objetivos propostos e a fundamentação teórica que embasa esta pesquisa.

No município de Corumbá, os setores de produção são claros, mineração, pecuária e turismo. Nesse sentido buscou-se por um empreendimento em ascensão, no setor de turismo de pesca, notório na cidade. Desta forma, este estudo buscou entender como surgiu a empresa JOICETUR, da empresária Joice Carla Santana Marques, brasileira, na faixa etária de 50 anos, com ensino fundamental, com renda individual e familiar superior a 7 salários mínimos, que possui um dos maiores empreendimentos do setor na cidade. Buscou-se entender se a empreendedora usou da teoria do effectuation na formação do seu negócio, analisando as cinco categorias que caracterizam a teoria do effectuation.

A análise dos objetivos tomou por base a seguinte categorização de ações empreendedoras: aproveitamento das oportunidades, mudança dos processos com base nas respostas do dia a dia, parcerias estabelecidas com stakeholders, a partir do "quem eu conheço", embasados nos cinco princípios Pássaro na mão, Perdas toleráveis, Colcha de retalhos, Fazer do limão uma limonada e Piloto de Avião, conforme descritos no quadro 7 apresentado a seguir, fazendo uma análise comparativa das tomadas de decisões tidas por parte da gestora, contrapostas aos princípios básicos do effectuation. 
Quadro 7-Análise por Categorias

\begin{tabular}{|c|c|c|c|c|c|}
\hline \multirow[b]{2}{*}{$\begin{array}{l}\text { UNIDADE DE SIGNIFICADO PELA ÓTICA: } \\
\text { CAUSATION VS EFFECTUATION. }\end{array}$} & \multicolumn{5}{|c|}{ CATEGORIAS } \\
\hline & $\begin{array}{l}\text { Pássaro } \\
\text { na mão }\end{array}$ & $\begin{array}{l}\text { Perdas } \\
\text { toleráveis }\end{array}$ & $\begin{array}{l}\text { Colcha } \\
\text { de } \\
\text { retalhos }\end{array}$ & $\begin{array}{l}\text { Fazer do } \\
\text { limão } \\
\text { uma } \\
\text { limonada }\end{array}$ & $\begin{array}{l}\text { Piloto } \\
\text { de } \\
\text { Avião }\end{array}$ \\
\hline $\begin{array}{l}\text { 1) Na realidade, eu costumo falar que eu caí de } \\
\text { paraquedas num negócio que já era negócio. }\end{array}$ & $\mathrm{X}$ & & & & \\
\hline $\begin{array}{l}\text { 2) Não procurei mercado; foi o mercado que me } \\
\text { procurou. }\end{array}$ & $\mathrm{X}$ & & & & \\
\hline $\begin{array}{l}\text { 3) Hoje o maior desafio que a empresa tem é fazer com } \\
\text { que em Corumbá os barcos hotéis sejam conhecidos } \\
\text { como destino de ecoturismo. }\end{array}$ & $X$ & & & & \\
\hline $\begin{array}{l}\text { 4) Quando você começa um negócio, tem que ter a } \\
\text { humildade de saber o que está fazendo. Afinal, } \\
\text { empresas muitas vezes quebram, não pelo dinheiro } \\
\text { que gastam e sim pelo dinheiro que investem errado. }\end{array}$ & & $\mathrm{X}$ & & & \\
\hline $\begin{array}{l}\text { 5) Banco não empresta dinheiro pra quem não tem } \\
\text { garantia, e na época eu não tinha. }\end{array}$ & & $\mathrm{X}$ & & & \\
\hline $\begin{array}{l}\text { 6) Pois você pode ver um cavalo branco galopando na } \\
\text { sua frente e deixar ele passar e lá na frente você vai se } \\
\text { arrepender de não ter galopado ou você vai montar e } \\
\text { dizer eu galopei. }\end{array}$ & & $\mathrm{X}$ & & & \\
\hline $\begin{array}{l}\text { 7) O quanto mais eu trabalhava, mais demanda } \\
\text { aparecia e eu tinha que ir me adaptando, me } \\
\text { estruturando pra dar conta de atender todos aos } \\
\text { turistas que queriam pescar e conhecer o pantanal. }\end{array}$ & & & $\mathrm{X}$ & & \\
\hline $\begin{array}{l}\text { 8) A empresa não pode olhar só o hoje e sim olhar pro } \\
\text { futuro, todo dia ele tem que visualizar como eu quero } \\
\text { estar daqui a vinte anos. }\end{array}$ & & & $\mathrm{X}$ & & \\
\hline $\begin{array}{l}\text { 9) Pra pagar a primeira parcela, pegamos dinheiro de } \\
\text { agiota. Segundo a casa foi vendida; terceiro, a moto } \\
\text { foi embora e quarta, o carro foi embora em } 2003 \text {. A } \\
\text { época mais difícil de tudo: a gente só tinha o barco, } \\
\text { pois tudo o que poderia foi investido. }\end{array}$ & & & & $\mathrm{X}$ & \\
\hline $\begin{array}{l}\text { 10) Hoje o maior desafio que a empresa tem é fazer } \\
\text { com que em Corumbá os barcos hotéis sejam } \\
\text { conhecidos como destino de ecoturismo. }\end{array}$ & & & & $\mathrm{X}$ & \\
\hline $\begin{array}{l}\text { 11) Meu público vai ficar velhinho e não vai conseguir } \\
\text { subir em beliche. Ele precisa de um banheiro com } \\
\text { barra de segurança, eu era chata. Todo ano mexia no } \\
\text { barco; se perguntar pra um cliente em que ano o } \\
\text { senhor chegou e o sofá era da mesma cor, ele vai dizer } \\
\text { que nenhum, pois todo ano tinha novidade. Eu sempre } \\
\text { surpreendia meu cliente. }\end{array}$ & & & & & $\mathrm{X}$ \\
\hline $\begin{array}{l}\text { 12) Hoje o maior desafio que a empresa tem é fazer } \\
\text { com que em Corumbá os barcos hotéis sejam } \\
\text { conhecidos como destino de ecoturismo. }\end{array}$ & & & & & $\mathrm{X}$ \\
\hline
\end{tabular}

Fonte: Dados coletados da entrevista 


\subsection{ANÁLISE POR CATEGORIZAÇÃO}

\section{Quem eu sou?}

Ao chegar a Corumbá, vinda do interior de São Paulo, onde predomina a fabricação de sapatos, a convite de um empresário para prestar serviços na área do turismo de pesca, onde trabalhou por oito anos adquirindo experiência, conhecimento e maturidade, com uma visão muito além do seu tempo, característica fundamental de um empreendedor, tentando implantar ideias novas, mas com certa resistência das pessoas às quais presta serviço, ela arriscou parte do que já tinha conquistado abrindo seu próprio negócio.

\section{Quem eu conheço?}

Em um ambiente onde havia muita procura e pouca oferta e os clientes queriam conhecer a Joice que sempre foi muito prestativa, pois ao decidir empreender, não tinha além da vontade, um carro e uma casa, o seu primeiro barco comprado a crédito, sem entrada, com um acordo firmado em um papel simples, para que fosse pago com o trabalho prestado. Os clientes já a conhecia pois vinha de uma empresa de turismo, onde sua função era vender pacotes de pesca e, por fim, os colaboradores. Alguns deles estão desde a abertura da empresa e quando começaram, a única garantia era a palavra dada, já que as incertezas fazem parte de todo começo.

\section{O que sei fazer?}

Ao trabalhar por oito anos prestando serviços, Joice adquiriu experiência, bagagem em forma de conhecimento, muito útil ao embarcar no desafio de desenvolver seu empreendimento. O maior desafio de qualquer empreendedor é lidar com pessoas - os stakeholders, sejam eles clientes, fornecedores ou colaboradores. Joice é uma líder nata admirada e seguida por pessoas à sua volta que com a experiência adquirida enquanto funcionária, fez com que a pequena empresa na época enxergasse um horizonte com inúmeras possibilidades de crescimento.

\section{Perdas toleráveis}

Com uma visão de futuro muito bem definida em um momento excepcional para o setor de turismo de pesca, Joice resolve investir no seu próprio barco. Além de ser conhecida como uma pessoa que cumpre seus compromissos, ela dispunha na época de um carro uma casa e uma moto. Dessa maneira, como dito anteriormente, ela faz uma proposta de compra a credito a um empresário que está vendendo um pequeno barco hotel que, na pior das hipóteses, caso o empreendimento desse errado, devolveria o barco e tentaria novamente o emprego, e hoje vinte anos depois a ideia é a mesma: há momentos em que a necessidade de investimento surge e não dá tempo para fazer muitas análises. É preciso arriscar, ouvir a intuição.

\section{Colcha de retalho}

Novos mercados e produtos surgem a partir de restrições e oportunidades geradas por pessoas que trazem recursos. É normal que muitas surpresas surgem no início de qualquer negócio, as incertezas do mercado, com uma visão sempre voltada pra o futuro está sempre se adaptando de acordo com as necessidades e a demanda e dessa maneira o empreendimento foi ganhando forma de acordo com o crescimento, se moldando de acordo com as exigência do mercado.

\section{Fazer do limão uma limonada}

Apesar do conhecimento adquirido, enquanto trabalhava como gerente, surpresas são inevitáveis. Afinal, o mercado tem vida própria. Sair da segurança de um trabalho encarando o 
desafio de se tornar empresária, é preciso ter pé no chão e muito controle emocional.

Naquele momento, nada existia além do conhecimento. Empreendedores são apaixonados pelo que fazem e esse amor é o principal combustível que os mantem cada vez mais animados (DORNELAS, 2000). Havia um sonho a ser conquistado que só se tornaria realidade com muita persistência e força de vontade. Pagar esse investimento foi um dos maiores desafios. Era um mercado em ascensão, o grande bum da pesca esportiva. Era uma questão de tempo até se consolidar no mercado, sendo necessário melhorar a cada temporada para dar conta de atender a todos os turistas que queriam pescar e conhecer o pantanal

\section{Piloto de avião}

Quando não se pode prever o futuro, deve-se tentar controlá-lo. Um negócio que nasce pequeno, mas com grande potencial dentro de um mercado em ascensão, assim nasce a JOICETUR, com um barco pequeno com apenas seis cabines. É fato que empreendedores podem controlar alguns fatores que são determinantes e a empresa passou por várias transformações, desde sua formação até os dias atuais. Afinal, quem não se atualiza está fadado ao fracasso. Dessa maneira, a empresa teve que visualizar o mercado do futuro, criar novos mercados em meio às necessidades e outra característica: dentro do seu planejamento há sempre opções que permitem a troca de estratégias de acordo com as contingências conforme necessário (PELAGIO e ROCHA, 2016). Com as mudanças na legislação de pesca e para os períodos de piracema, há quatro anos vem sendo implantado o turismo ecológico, de modo que se possam superar os períodos em que a pesca não pode ser praticada, conforme a legislação vigente.

O objetivo deste estudo foi buscar o entendimento das características empreendedoras e se elas estão preconizadas sob a ótica do effectuation. Vale ressaltar a título de reforço, que o modelo causual é imprescindível a toda e qualquer organização e que um modelo não substitui o outro, mas se complementam a partir do crescimento. Pode-se entender que nem tudo que está na teoria, os pequenos empreendedores cumprem à risca, até mesmo por falta de experiência formal ou por melhores adaptações do seu negócio à realidade do momento. Todavia, por caminhos diferentes e usando da criatividade, conseguem ultrapassar determinados obstáculos formais iniciais, que logo acabam sendo reincorporados no sistema operacional da empresa, devido ao seu crescimento e à necessidade de modernização. O caso da Joicetur se encaixa neste contexto, conforme sua fala.

Dessa maneira, quebra-se o paradigma de que para empreender é necessário um estudo de mercado, captação de um alto valor de recursos financeiros e desenvolvimento de um plano de negócios, como manda a lógica causual. O effectuation se opõe a essa lógica, dando oportunidades reais e claras a todos que disponham de uma ideia inovadora, seja de um produto ou serviço. Num país onde $1 / 4$ dos brasileiros empreende de alguma maneira, mas apenas $4.8 \%$ tem formação universitária, vale a pena ressaltar que a lógica causual é imprescindível em qualquer empresa, quando em proporções maiores. (GEM, 2018, p. 14).

Os autores buscaram reconhecer o uso da teoria do effectuation nas tomadas de decisão que levaram à criação da empresa JOICETUR pesca e turismo.

Com base na teoria de effectuation a empresária entrevistada possui características empreendedoras capaz de tomar decisões em um ambiente cheio de incertezas, de acordo com as contingências do momento, visando não maximizar lucros, mas reduzir perdas financeiras. De acordo com o effectuation, o empreendedor por meio de ações cria resultado a partir destas 
combinações de recursos à medida que reduz as incertezas que o cerca (TASIC, 2007). São de fácil percepção as características apresentadas por Pelagio e Rocha (2016) que demonstram a posição effectual e suas atitudes.

\section{VISÃO DE FUTURO}

Que vê o futuro como ações de agentes obstinados. Empreendedores desse tipo não gostam de pesquisa de mercado. Fazem o futuro acontecer de acordo com as necessidades: Joice - "tinha muita gente querendo vir pescar no pantanal... não procurei o mercado foi o mercado que me procurou, naquela época tinha muitas pessoas que queriam fazer a pesca esportiva tinha muita procura e pouca oferta" vendo nessa necessidade a oportunidade de empreender.

\section{BASE PARA COMPROMETIMENTO}

Um empreendedor sabe que dinheiro é consequência de um trabalho bem feito. Então emprega o coração em qualquer projeto que se proponha a fazer. A satisfação pessoal de auto realização é a maior recompensa: Joice - "eu falo que quando você põe o seu nome na empresa faz com que até as pessoas que trabalham honrem esse nome e o desafio sempre foi fazer com que esse nome estivesse à altura das pessoas que o procuram".

\section{BASE PARA ADQUIRIR STAKEHOLDERS}

Os objetivos são definidos de acordo com a visão de quem ingressa: Joice - "boa parte das pessoas que trabalham aqui não sabem ler e escrever são pessoas que em outra área de trabalho na cidade teriam pouco aproveitamento, mas são profundos conhecedores rio Paraguai conhecem o pantanal como a própria casa essas pessoas são as responsáveis por mostrar nossas maravilhas aos turistas que se encantam com tanta experiência”. Dessa maneira, ela adapta não o colaborar com a função e sim a função com o colaborador.

\section{PLANEJAMENTO}

São escolhidos caminhos que permitem mais opções possíveis dando maior flexibilidade em relação às contingências, onde surpresas são vistas como fonte de oportunidade.

\section{PREDISPOSIÇÃO AO RISCO}

Calcula o potencial de perda e não arrisca mais do que pode dispor a perder. É fato dizer que a intuição de um empreendedor é muito aguçada: Joice - "em dois mil e dezesseis surgiu a oportunidade de comprar a Kaiamã. Foi um investimento de risco afinal o barco estava parado quando surgiu a proposta e assim acontece... tem algumas oportunidades de investimentos que acontecem sem você esperar e essas atitudes vai dizer se a sua empresa cresce ou não".

\section{ATITUDE COM EMPRESAS EXTERNAS}

Parceria constrói o seu mercado juntamente com clientes fornecedores e até mesmo concorrentes: Joice - "se você me pedir te apresento qualquer barco hotel tenho acesso a todos e todos tem acesso aо meu ... acho que o empresário inteligente é aquele que consegue num ambiente proteger os ideais de todos e no outro ambiente proteger o seu... claro que de maneira competitiva eu quero ser a melhor naquilo que faço".

\section{CONSIDERAÇÕES FINAIS}

Pelo estudo procedido, em conformidade com os autores listados no referencial teórico e com base na pesquisa de campo junto à empresária Joice, ficou entendido que as teorias causual e a effectuation possuem grande importância para que um empreendimento possa ter 
sucesso durante a sua trajetória num determinado empreendimento. Todavia, há também que se considerar que dependendo da criatividade do pequeno empreendedor, o modelo effectuation é o que mais possibilita o início de um novo negócio. Isso, entretanto, não inviabiliza que tal negócio alcance o sucesso desejado usando o modelo causation.

Os momentos de incertezas e dificuldades são comuns em todas as esferas de atividades empreendedoras, contudo, por caminhos formais ou informais, dependendo-se da procura e da oferta, muitos atos considerados quase intransponíveis ao empreendedor acabam sendo superados.

Este estudo demonstrou que a teoria effectuation e causation podem funcionar juntas, não significando, por outro lado, que separadamente elas não possam levar um empreendimento a bom termo. O sucesso aliado ao crescimento empresarial faz com que se possam unir ferramentas que venham a ajudar muito o empreendedor a encontrar novos caminhos que o levem a pontos mais promissores. Isso depende muito de cada um.

No caso estudado, por caminhos diferentes, a atual empresária conseguiu chegar aonde pretendia e isso ela deixa claro nas suas palavras. Que não foi nada fácil, ela mesma afirma, entretanto, não se constituiu obstáculo para que ela desistisse dos seus verdadeiros intentos, mostrando, dessa forma, como age um verdadeiro empreendedor, fazendo acontecer aquilo que um dia foi apenas um sonho.

Recomenda-se para estudos futuros, a análises de outras organizações em diferentes contextos e regiões para maiores esclarecimentos em relação a tomada de decisão sob a ótica do effectuation.

\section{Referências}

ALIANÇA EMPREENDEDORA. 23 de jun. de 2018. Disponível em: http://aliancaempreendedora.org.br/o-que-as-raizes-da-teoria-effectuation-de-sarassarasvathy-e-a-sevirologia-brasileira-tem-a-dizer-ao-microempreendedor/. Acesso em $20 \mathrm{fev} 2019$.

BOGDAN, Robert e BIKLEN, Sarri. Investigação qualitativa em Educação: uma introdução a Teoria e aos métodos.Trad. Maria João Álvares et al. Portugal: Porto Editora, 1994.

BRITO, Claudio. Empreendedorismo. Disponível em: <http://claudiobrito.com/empreendedorismo>. Acesso em: 10 maio 2019.

CERVO, Amado Luiz. Metodologia científica/ Amados Luiz Cervo, Pedro Alcino Bervian, Roberto da Silva. 6. ed. São Paulo: Person Pretince Hall, 2007.

DINIZ, Abílio. Biografia. São Paulo, 2018. Disponível em: <http://abiliodiniz.com.br/lideranca/empreendedorismo/caracteristicas-pessoais/> Acesso em: 19 fev. 2019.

DORNELAS, José Carlos Assis. Empreendedorismo: transformando ideias em negócios. 3. ed. São Paulo: Campus, 2000. 
FILION, L. J. O planejamento do seu sistema de aprendizagem empresarial: Identifique uma visão e avalie o seu sistema de relações. RAE, São Paulo, v. 31, n. 3, p. 63-71, jul./set.1991.

FRANCO, Maria Laura Puglisi Barbosa. Análise de conteúdo. Brasília: Plano Editora, 2003.72p

GEM - GLOBAL ENTREPRENEURSHIP MONITOR 2017. Disponível em: $<$ https://m.sebrae.com.br/Sebrae/Portal\%20Sebrae/Anexos/Relat\%C3\%B3rio\%20Executivo\% 20BRASIL_web.pdf >. Acesso em: 20 out. 2019.

GERBER, Michael E. O mito do empreendedor: como fazer de seu empreendimento um negócio bem-sucedido. São Paulo: Saraiva, 1996.

HAMMER, Michael, CHAMPY, James. Reengineering the corporation. New York: HarperBusiness, 1994.

HISRICH, R.; PETERS, M. P. Empreendedorismo. 5. ed. Porto Alegre: Bookman, 2004.

IBGE. Estimativa Populacional. Disponível em: http://www.ibge.gov.br/home/estatistica/populacao/estimativa2014/estimativa_tcu.sh Acesso em: 13 maio 2019.

LAVILLE, C.; DIONNE, J. A construção do saber: manual de metodologia da pesquisa em ciências humanas. Belo Horizonte: UFMG, 1999.

MINAYO, Maria Cecília de Souza (org.) DESLANDES, Suely Ferreira, CRUZ NETO, Otávio, GOMES, Romeu. Pesquisa Social: teoria, método e criatividade. Petrópolis, RJ:Vozes,1994.

PELAGIO, E. A; ROCHA. Modelo de decisão e efectuation:uma alternativa para o estudo da criação de novos negócios .Natal: HOLOS, 1999.

SARASVATHY, S. Causation and Effectuation: Towards a theoretical shift from economic inevitability to entrepreneurial contingency. Academy of Management Review. V. 26. 2001.

SARASVATHY, S. D. What makes entrepreneurs entrepreneurial. Virginia: Darden business Publishing, 2001

TASIC, I. A. B. Estratégia e empreendedorismo: Decisão e Criação sob incerteza. Dissertação de Mestrado. São Paulo: FGV, 2007.

TIMMONS, J. A. New venture creation. 4. ed. Boston: Irwin McGraw-Hill, 1994.

TRIVIÑOS, Augusto Nibaldo Silva. Três enfoques na pesquisa em ciências sociais: o positivismo, a fenomenologia e o marxismo. In: . Introdução à pesquisa em ciências sociais. São Paulo: Atlas, 1987.

YIN, Robert K. Estudo de caso: planejamento e métodos. 4 ed. Porto Alegre: Bookman, 2010 